\title{
Self-rated health and public health: a critical perspective
}

\section{Andrea E. Bombak*}

Department of Community Health Sciences, University of Manitoba, Winnipeg, MB, Canada

*Correspondence: umbombak@cc.umanitoba.ca

Edited by:

Ingrid A. Oakley-Girvan, Cancer Prevention Institute of California, USA

Reviewed by:

Ingrid A. Oakley-Girvan, Cancer Prevention Institute of California, USA

\section{INTRODUCTION}

Self-rated health (SRH) is a simple, easy to administer measure of general health. It is a valid and reliable measure among those without cognitive impairment. Initially, it replaced clinical assessments in survey research (1). It is commonly used in psychological research, clinical settings, and in general population surveys. SRH is typically measured as a single-item, the most common wording of which is "In general, would you say your health is" with the response items "excellent," "very good," "good," "fair," or "poor." Early studies using SRH involved assessing the relationship between SRH with sociodemographic, physical health, and psychosocial variables (e.g., 2, 3). Additional uses of SRH involved investigating relationships between health constructs, sociodemographic, physi$\mathrm{cal}$, and psychosocial variables, clarifying measurement issues, attempting to explain health and illness behavior, or describing populations' health (e.g., 2-4). SRH was found to be at least moderately associated with physicians' assessments of health $(2,4-8)$. SRH allows respondents to prioritize and evaluate different aspects of their health, maximizing the measure's sensitivity to respondent views of health (9). SRH's somewhat abstract nature also affords researchers the opportunity to examine the cognitive processes involved in evaluating self-health (9). A significant, independent effect of SRH on mortality has been demonstrated in numerous studies and diverse populations (10-12). Other health outcomes including chronic disease incidence, diabetes complications, physical and cognitive functional limitations, health services use, and clinical biomarkers have also been investigated (13-20). A large body of literature concerning SRH, its determinants, and its outcomes has accumulated from studies conducted throughout the world.
Recently, public health researchers have begun to deploy SRH either implicitly or explicitly to gage individuals' willingness to engage in behavior modification. This paper critically assesses the literature on SRH and health behaviors. It examines the theoretical and ethical utility of SRH as a tool in healthrelated behavior modification.

\section{SRH AND HEALTH BEHAVIORS}

A complex relationship exists between SRH and health-related behaviors. Healthrelated behaviors included in SRH studies often include smoking status, dietary assessments, physical activity, body mass index (BMI) or presence of obesity, and alcohol activity (21). Often these health behaviors are included as covariates, rather than explanatory or outcome variables (e.g., 18, 21, 22). Likewise, health-related behaviors have been used as control variables in studies exploring SRH and mortality. Health behaviors have been shown to mediate the relationship between SRH and mortality, and this effect often differs by gender and/or duration of effect $(15,23,24)$. Other studies, however, have only seen a fairly weak mediating influence of health behaviors on SRH and mortality (25-27). Some studies have found only weak or irrelevant associations with SRH (28-30). Conflicting findings have emerged concerning SRH and all of smoking, alcohol consumption, and dietary behaviors $(17,20,31-43)$. Layes et al. (44) determined that individuals who engaged in healthy lifestyles were actually more likely to be pessimist regarding their health statuses.

Manderbacka (45) found some Finnish adults clearly have adopted health messaging and incorporated risk behaviors and fitness-centric responses in their self-evaluations. Krause and Jay (46) found younger and better educated Americans were more likely to incorporate health behaviors in their assessments of self-health, and similar age-related findings were found among
Australian women (47). These findings reflect the groups in which health messaging may have had the highest rates of absorption. The reviewed studies provide some evidence that health behaviors affect SRH. However, the relationship is ambiguous, not always in expected directions, and mediated by age, gender, and ethnicity. Such studies also do not consider the manner through which some health behaviors, while ostensibly health-damaging, may serve to promote pleasure and stress-relief, and thus may be mental-health enhancing.

\section{SRH AND BEHAVIOR MODIFICATION}

In reviewing the literature on SRH and health behaviors, it is evident that some studies adopt a corrective attitude relating to SRH. They seek to determine the congruence of an individual's assessment of health with an objective rating of health based on medical diagnoses or health behaviors. These studies appear not to be designed to better understand SRH but rather to use it to assess individuals' level of "awareness" regarding their health status. It is assumed that those who rate their health favorably, in spite of objective indications of poor health, must have their SRH corrected through education and the adoption of appropriate behavior changes.

For example, researchers have adopted a critical tone in studies in which respondents have reported generally favorable health while suffering from chronic conditions such as diabetes, hypertension, and obesity and adopting risky health behaviors such as smoking, inactivity, lack of produce consumption, or soda consumption among Australian Aboriginal, and American Appalachian, Black, Hispanic, and Latino populations (48-51). For example, Griffith and colleagues refer to the distortion they believe is evident in Appalachians' SRH. Appalachia residents rate their health more highly than their health behaviors 
and objective health status might suggest. This is viewed as an impediment to initiating behavior change, and thus the authors recommend that "Education, therefore, must be targeted at promoting appropriate views of health and the need for improved health...formation and delivery of new public messages and programs for rural Appalachians should be focused on people who are unhealthy and have poor health behaviors, but believe they are healthy" (2011, 7 of 8). That is, because respondents' SRH was not associated with objective health measures, it is "inaccurate" and must be corrected. Participants will then be willing to acknowledge their "actual" poor health and engage in appropriate behavior change.

Interestingly, Kepka et al. (48) acknowledges that SRH is positively associated with health beneficial behaviors in recent Latino immigrants, although more frequent engagement in health behaviors is deemed necessary. Despite its relationship to behavioral factors, the authors are concerned that lower SRH does not predict higher BMI. The authors are further troubled that respondents reported improvements or stability to their quality of life and health following immigration, despite weight gain. This suggests a particularly narrow definition of health. As stated by the authors, "health education strategies should be targeted at recent Latino immigrants...to heighten awareness regarding overweight and obesity risk and help individuals more accurately link perceptions of one's health and BMI" (48, p. 541). Similarly, Burroughs et al. (49) suggest that the optimist SRH reported by overweight African Americans may be the result of lower levels of weight dissatisfaction and greater social acceptance of excess weight. This degree of self-acceptance is considered dangerous to health by the authors. They suggest it has important practice implications "as individuals who do not perceive that they are overweight are unlikely to take action to control or lose weight" (49, p. 1404).

The underlying assumption of the reported implications of these studies is the need for education concerning individuals' own perceptions of health. It is proposed that the overly health-optimist individuals must be educated regarding their health status in order to ensure that they more accurately assess their health. It is presumed that this "accurate" evaluation of poor health status will motivate individuals to engage in behavioral modification, despite, for example the Latino immigrants' association between at least some degree of healthful behavior and SRH (48). Selfacceptance or resilience regarding health when faced by disease or socioeconomic difficulties appears to not be considered a positive coping method. Other, holistic determinants of health, to which individuals may refer when rating health, are not considered. Instead, researchers focus on the need for individuals to take responsibility for conceptualizes of health held by the researchers, and to initiate changes to meet these external ideals.

\section{IMPLICATIONS OF DEPLOYING SRH IN BEHAVIOR MODIFICATION}

Self-rated health is inherently a subjective measure of internal perceptions and priorities. Thus, the use of SRH to rectify individuals' impressions of their health, in order to motivate behavior change, suggests a problematically non-salutogenic, individualistic, and moralist perspective. This utilization of SRH has important ethical and practice implications.

In their review on SRH and mortality, Idler and Benyamini (11) speculated that one of the dimensions of SRH that may be inaccessible to researchers was individuals' knowledge of health-related behaviors and adherence. Researchers have subsequently used this potential relationship to lend SRH studies clinical and applied significance. This presumes that a greater understanding of SRH will aid in the development of more effective behavioral interventions. In turn, these expectations are founded on the assumption that individuals with lessthan-optimal health must first be made to recognize their problematic health status, acknowledge their need for health behavior modification, and then choose to undertake more salubrious lifestyle choices.

Within this context, $\mathrm{SRH}$ is no longer used to explore an individual's unique perceptions of their health or as a proxy for clinical health. Instead, individuals will be expected to rate their health according to others' standards, identify deficiencies, and then correct their behaviors to achieve "better" health. As individuals may incorporate numerous factors in their self-perceptions of health, this assumes individuals have control over exceptionally comprehensive conceptualizations of health. Significantly, health has taken on a great deal of moral weight. Labeling someone "unhealthy" has significant social ramifications, and it is imperative researchers be respectful of the daily contexts of individuals' choices and their unique perspectives on wellbeing.

Of importance is that no simple relationship exists between SRH and lifestyle choices. Rather, SRH and behavior may be mediated by sociodemographic or cultural factors, and more positive SRH may not seemingly be produced by seemingly "health-conducive" behaviors. To assess willingness to engage in behavior modification, a more direct measure regarding individuals' lifestyle health behavior modification intentions may be necessary. Furthermore, SRH researchers often employ a limited, biomedical definition of "health," which ignores the multi-faceted nature of SRH. Perhaps unintentionally, they also seek to "correct" the perspective of the populations they are studying. This is particularly problematic in studies conducted in disadvantaged or minority populations, wherein cultural discrepancies between researchers and participants in definitions of health may exist. The validity and value of SRH has frequently been related to its established relationship with mortality, which is often found to be independent of clinical or physician assessments and to surpass these measures in predictive power. Clearly, individuals are capable of recognizing their own state of wellbeing, regardless of whether this reflects the views held by practitioners and researchers, and they may rely on dimensions of health inaccessible to researchers $(2,52)$. Of paramount importance, researchers must consider whether it is ethical to convince individuals that their health is poorer than they perceive, if this affects mortality and morbidity risk.

Risky health behaviors may relieve stress. As such, they may be "health"-motivated in a particular sociocultural context. They are not necessarily actions borne of ignorance. While incongruent with objective measures of health, some positive ratings may be demonstrative of resilience. It is these complex inquiries that are too often unexplored in preventive health, and these are the fascinating and essential avenues of research available to future investigators of SRH. 


\section{ACKNOWLEDGMENTS}

The author has received funding from the Manitoba Graduate Scholarship (MGS) (2008-2010), Social Sciences and Humanities Research Council (SSHRC) (2009-2010), Manitoba Health Research Council (MHRC) (2010-2012), Western Regional Training Centre for Health Services Research (WRTC) (2010-2011), and the Canadian Institutes of Health Research (CIHR) Doctoral Research Award (2012-2014).

\section{REFERENCES}

1. Strawbridge WJ, Wallhagen MI. Self-rated health and mortality over three decades: results from a time-dependent covariate analysis. Res Aging (1999) 21:402-16.

2. Maddox GL. Some correlates of differences in selfassessment of health status among the elderly. $J$ Gerontol (1962) 17:180-5.

3. Garrity TF, Somes GW, Marx MB. Factors influencing self-assessment of health. Soc Sci Med (1978) 12:77-81.

4. Ware JE, Davies-Avery A, Donald CA. Conceptualization and Measurement of Health for Adults in the Health Insurance Study: Vol. V, General Health Perceptions. Santa Monica: Rand (1978). [R-1987/5-Hew].

5. Suchman EA, Phillips BS, Streib GF. Analysis of the validity of health questionnaires. Soc Forces (1958) 36:223-32.

6. Heyman DK, Jeffers FC. Effect of time lapse on consistency of self-rated health and medical examinations of elderly persons. J Gerontol (1963) 18:160-4.

7. LaRue A, Bank L, Jarvik L, Hetalnd M. Health in old age: how do physicians' ratings and self-ratings compare? J Gerontol (1979) 34:687-91.

8. Idler EL, Hudson SV, Leventhal H. The meanings of self-ratings of health: a qualitative and quantitative approach. Res Aging (1999) 21:458-76.

9. Bjorner JB, Fayers P, Idler E. Self-rated health. In: Fayers P, Hays R, editors. Assessing Quality of Life in Clinical Trials. Oxford: Oxford University Press (2005). p. 309-23.

10. Mossey JM, Shapiro E. Self-rated health: a predictor of mortality among the elderly. Am J Public Health (1982) 72:800-8.

11. Idler EL, Benyamini Y. Self-rated health and mortality: a review of twenty-seven community studies. J Health Soc Behav (1997) 38:21-37.

12. BenyaminiY, Idler EL. Community studies reporting association between self-rated health and mortality: additional studies, 1995 to 1998. Res Aging (1999) 21:392-401.

13. Fylkesnes K. Determinants of health care utilization - visits and referrals. Scand J Soc Med (1993) 21:40-50.

14. Pijls LTJ, Feskens EJM, Kromhout D. Self-rated health, mortality, and chronic diseases in elderly men: the Zutphen Study. Am J Epidemiol (1993) 138:840-8.

15. Idler EL, Russell LB, Davis D. Survival, functional limitations, and self-rated health in the NHANES
I Epidemiologic Follow-Up Study, 1992. Am J Epidemiol (2000) 152:874-83.

16. Whitfield KE, Allaire JC. Relationships among health factors and everyday problem solving in African Americans. Health Psychol (2004) 23:641-4.

17. Tomten SE,Høstmark AT. Self-rated health showed a consistent association with serum HDL-cholesterol in the cross-sectional Oslo Health Study. Int J Med Sci (2007) 4:278-87.

18. Balasubramanyam A, Rao S, Misra R, Sekhar RV, Ballantyne CM. Prevalence of metabolic syndrome and associated risk factors in Asian Indians. J Immigr Minor Health (2008) 10:313-23.

19. Hayes AJ, Clarke PM, Glasziou PG, Simes RJ, Drury PL, Keech AC. Can self-rated health scores be used for risk prediction in patients with type 2 diabetes? Diabetes Care (2008) 31:795-7.

20. Haseli-Mashhadi N, Pan A, Ye X, Wang J, Qi $\mathrm{Q}$, Liu Y, et al. Self-rated health in middle-aged and elderly Chinese: distribution, determinants and associations with cardio-metabolic risk factors. BMC Public Health (2009) 9:368. doi: 10.1186/1471-2458-9-368

21. Delpierre C, Lauwers-Cances V, Datta GD, Berkman L, Lang T. Impact of social position on the effect of cardiovascular risk factors on self-rated health. $A m$ J Public Health (2009) 99:1278-84.

22. Huh J, Prause JA, Dooley CD. The impact of nativity on chronic diseases, self-rated health and comorbidity status of Asian and Hispanic immigrants. J Immigr Minor Health (2008) 10:103-18.

23. Idler EL, Angel RJ. Self-rated health and mortality in the NHANES-I epidemiologic follow-up study. Am J Public Health (1990) 80:446-52.

24. Bath PA. Differences between older men and women in the self-rated health-mortality relationship. Gerontologist (2003) 43:387-95.

25. Idler EL, Kasl S. Health perceptions and survival: do global evaluations of health status really predict mortality? J Gerontol (1991) 46:S55-65.

26. Mackenbach JP, Simon JG, Looman CWN, Joung IMA. Self-assessed health and mortality: could psychosocial factors explain the association? Int $J$ Epidemiol (2002) 31:1162-8.

27. Benjamins MR, Hummer RA, Eberstein IW, Nam CB. Self-reported health and adult mortality risk: an analysis of cause-specific mortality. Soc Sci Med (2004) 59:1297-306.

28. Eriksson I, Undén A-L, Elofsson S. Self-rated health Comparisons between three different measures. Results from a population study. Int J Epidemiol (2001) 30:326-33.

29. Maclean H, Glynn K, Cao Z, Ansara D. Personal health practices. BMC Women's Health (2004) 4(Suppl 1):S4. doi: 10.1186/1472-6874-4-S1-S4

30. Singh-Manoux A, Martikainen P, Ferrie J, Zins M, Marmot M, Goldberg M. What does self rated health measure? Results from the British Whitehall II and French Gazel Cohort Studies. J Epidemiol Community Health (2006) 60:364-72.

31. Ross CE, Bird CE. Sex stratification and health lifestyle: consequences for men's and women's perceived health. J Health Soc Behav (1994) 35:161-78.

32. Møller L, Kristensen TS, Hollnagel H. Self rated health as a predictor of coronary heart disease in Copenhagen, Denmark. J Epidemiol Community Health (1996) 50, 423-8.
33. Shetterly SM, Baxter MSJ, Mason LD, Hamman RF. Self-rated health among Hispanic vs NonHispanic white adults: the San Luis Valley Health and Aging Study. Am J Public Health (1996) 86:1798-1801.

34. Klein BEK, Klein R, Moss SE. Self-rated health and diabetes of long duration: the Wisconsin Epidemiologic Study of Diabetic Retinopathy. Diabetes Care (1998) 21:236-40.

35. Benyamini Y, Leventhal EA, Leventhal H. Gender differences in processing information for making self-assessments of health. Psychosom Med (2000) 62:354-64.

36. Manor O, Matthews S, Power C. Self-rated health and limited longstanding illness: inter-relationships with morbidity in early adulthood. Int J Epidemiol (2001) 30:600-7.

37. Goldman N, Glei DA, Chang M-C. The role of clinical risk factors in understanding self-rated health. Ann Epidemiol (2004) 14:49-57.

38. Jonnalagadda SS, Diwan S. Health behaviors, chronic disease prevalence and self-rated health of older Asian Indian immigrants in the U.S. J Immigr Health (2005) 7:75-83.

39. Undén A-L, Elofsson S. Do different factors explain self-rated health in men and women? Gend Med (2006) 3:295-308.

40. Lim W-Y, Ma S, Heng D, Bhalla V, Chew SK. Gender, ethnicity, health behavior and self-rated health in Singapore. BMC Public Health (2007) 7:184. doi: 10.1186/1471-2458-7-184

41. Ramkumar A, Quah JLS, Wong T, Yeo LSH, Nieh C-C, Shankar A, et al. Self-rated health, associated factors and diseases: a community-based cross-sectional study of Singaporean adults aged 40 years and above. Ann Acad Med Singapore (2009) 38:606-7.

42. Ruthig JC, Hanson BL, Ludtke RL, McDonald LR. Perceived barriers to health care and health behaviors: implications for Native American elders' selfrated health. Psychol Health Med (2009) 14:190-200.

43. Cotter KA, Lachman ME. Psychosocial and behavioral contributors to health: age-related increases in physical disability are reduced by physical fitness. Psychol Health (2010) 25:805-20.

44. Layes A, Asada Y, Kepart G. Whiners and deniers what does self-rated health measure? Soc Sci Med (2012) 75:1-9.

45. Manderbacka K. Examining what self-rated health question is understood to mean by respondents. Scand J Soc Med (1998) 26:145-53.

46. Krause NM, Jay GM. What do global self-rated health items measure? Med Care (1994) 32:930-42.

47. Shadbolt B. Some correlates of self-rated health for Australian women. Am J Public Health (1997) 87:951-6.

48. Kepka D, Suchi Ayala GX, Cherrington A. Do Latino immigrants link self-rated health with BMI and health behaviors? Am J Health Behav (2007) 31:535-44.

49. Burroughs VJ, Nonas C, Sweeney CT, Rohay JM, Harkins AM, Kyle TK, et al. Self-reported comorbidities among self-described overweight AfricanAmerican and Hispanic adults in the United States: results of a national survey. Obesity (2009) 16:1400-6.

50. Griffith BN, Lovett GD, Pyle DN, Miller WC. Selfrated health in rural Appalachia: health perceptions are incongruent with health status and health behaviors. BMC Public Health (2011) 11:229. doi: 10.1186/1471-2458-11-229 
51. Spurling G,Hayman N. Self-rated health in an urban indigenous primary care setting: implications for clinicians and public health policy. Aust NZJ Public Health (2010) 34:598-601.

52. Quesnel-Vallée A. Self-rated health: caught in the crossfire of the quest for 'true' health? Int J Epidemiol (2007) 36:1161-4.
Received: 25 February 2013; accepted: 05 May 2013; published online: 20 May 2013.

Citation: Bombak AE (2013) Self-rated health and public health: a critical perspective. Front. Public Health 1:15. doi: 10.3389/fpubh.2013.00015

This article was submitted to Frontiers in Epidemiology, a specialty of Frontiers in Public Health.
Copyright (c) 2013 Bombak. This is an open-access article distributed under the terms of the Creative Commons Attribution License, which permits use, distribution and reproduction in other forums, provided the original authors and source are credited and subject to any copyright notices concerning any thirdparty graphics etc. 